REVISTA DE DERECHO UNED, núm. 1, 2006

\title{
LA FUNCIÓN DEL JUEZ COMO CREADOR DE NORMAS JURÍDICAS EN EL DERECHO INTERNACIONAL PRIVADO
}

\author{
Jorge Alberto Silva Silva ${ }^{1}$
}

Sumario: I. INTRODUCCIÓN.-II. ENUNCIADOS JURÍDICOS QUE CARECEN DE SIGNIFICADO PREDETERMINADO.-III. TEXTOS CUYO SIGNIFICADO LE CORRESPONDE AL APLICADOR.-IV. INTERPRETACIÓN Y CREACIÓN NORMATIVA.-a) Criterios formalisticos y cognitivos.-b) Criterios materiales o escépticos e intermedios.-V. INTERPRETACIÓN Y CREACIÓN EN EL DERECHO INTERNACIONAL PRIVADO.-VI. INTERPRETACIÓN, CALIFICACIÓN Y APLICACIÓN DEL DERECHO EXTRANJERO.-VII. LA ARGUMENTACIÓN COMO UN MEDIO PARA DEFINIR SIGNIFICADOS.-VIII. LA ARGUMENTACIÓN EN EL DERECHO INTERNACIONAL PRIVADO.-IX. A MANERA DE CONCLUSIÓN.

\section{INTRODUCCIÓN}

Cuando un niño dice que dos por dos son cuatro su afirmación es verdadera, nadie negará o dirá que es falso lo que el niño afirma; pero cuando el juez afirma que es justo que el padre que abandonó a su hijo pequeño le entregue el treinta por ciento de lo que gana en concepto de manutención, no puede decirse que eso sea una verdad. Alguien podría decir que es justo, mientras que otro, podría negar la

${ }^{1}$ Profesor en áreas de Derecho internacional privado, Presidente de la Asociación Mexicana de Profesores de Derecho Internacional Privado. Agradezco al Prof. Adrián Renteria, de la Universidad de Insubria (Como, Italia), haber leído el manuscrito y sugerirme correcciones de estilo, mismas que he tomado en cuenta. 
justicia y adecuación a la ley. Aunque en un caso como este lo que la lógica formal no podría decirnos es si es o no justo lo resuelto por el juez, por lo que subsiste la cuestión de saber ¿cómo se puede afirmar que el juez ha llevado a la ejecución lo que dice o prescribe la ley?

Comienzo con lo anterior porque aun se suelen escuchar en el foro mexicano pensamientos en los que pervive la creencia de que solo el legislador puede crear las normas, en tanto que el juzgador, solo debe aplicarlas. Con mayor frecuencia también se escucha que interpretar significa desentrañar el sentido de la norma (García Máynez, Puig y Peña) o indagarlo (Castán Tobeñas), y que para interpretar se requiere recurrir a la intención del legislador o de la ley ${ }^{2}$. Se trata de afirmaciones en las que pervive el mito que predica que el legislador ha previsto todo lo inimaginable que tenga que ser regulado por el derecho, que cada palabra establecida por el legislador tiene un significado propio que le es inmanente, que las palabras del juez solo son la boca del legislador, y que el juez, que carece de discrecionalidad $^{3}$, solo tiene que individualizar lo que prescribe la ley (algo semejante a que dos por dos siempre son cuatro) etc. Esto es, todo esto supone que la ley siempre tiene la respuesta correcta, la «verdadera" incluso, que solo puede haber una única respuesta, y que es el juez, como el niño de nuestro ejemplo, el que tiene que decir esa "verdad», "pasándola del legislador a los interesados».

El hecho es conforme a las ideas recordadas, los significados de un enunciado establecido en la ley parecen ser fáciles de percibir, de «descubrir su significado». Si la ley dice que el padre debe pagar los alimentos de su hijo, ahí no hay nada controversial o ambiguo: el padre tiene que pagar; si la ley dice que un cheque debe tener la mención de ser cheque, es evidente que la disposición es clara, no hay nada ambiguo o que tenga que aclararse; si la ley dice que el que priva de la vida a otro debe ir a la cárcel, el enunciado legal es bastante claro; etc. Se trata de enunciados que prescriben que el juez solo tiene que acatar lo que el legislador dice. Lo que se advierte porque el significado de los enunciados es "claro», simplemente en estos, no hay nada que el juez pueda aportar, o que bajo el pretexto de la interpretación se pueda alterar el significado inmanente que tiene preconcebido cada palabra que emplea el legislador. En el fondo, el juez carece de discrecionalidad.

2 Sobre la intención véase Joseph Raz, "La intención en la interpretación», Isonomía, Núm. 9, octubre 1998.

${ }^{3}$ Adrían Rentería Díaz, Il laberinto della giustizia, Franco Angeli, Milano, 2000, p. 37. Existe versión al castellano: Discrecionalidad judicial y responsabilidad (Fontamara, 2001, México), pero he recurrido a la versión italiana, por parecerme más clara. 
A pesar de la aseveración anterior, basta revisar las disposiciones jurídicas vigentes en México para encontrar que el legislador oficial introduce textos cuyo contenido no es fácil conocer, ni su significado está determinado previamente, ni son denotativos; se trata de hipótesis en las que se hace necesario que el operador jurídico (normalmente el juez) establezca el significado creando con ello, no solo este, sino su contenido. Esto es, no «desentraña» o «descubre» el sentido de la ley, sino que lo define.

Interpretar, afirma Rolando Tamayo y Salmorán, consiste en un acto de significación, esto es, por el cual se asigna un significado específico a ciertos hechos, signos, fórmulas o palabras» ${ }^{4}$.

Una importancia especial parecen tener los textos que corresponden al Derecho internacional privado $(D I P r)$, pues en estos (indeterminados y ambiguos como en los de otras disciplinas), la diversidad de textos y significados no suelen precisarse por el legislador. Se trata de expresiones a las que el juez tiene que atribuirle un significado, pues, de otra manera, se quedarían como palabras sin sentido.

Para que a esos textos o sintagmas se les atribuya un significado es necesario un procedimiento que culmine con la atribución del mismo (de significado), lo que, además, implica un proceso de creación normativa, actividad que no corre necesariamente a cargo del legislador, sino del juzgador.

Esta actividad se complica en el $D I P r$, primero, con las conocidas como normas de conflicto y las normas materiales locales y, segundo, con el ordenamiento extranjero designado como aplicable ${ }^{5}$.

A este tipo de problemas me quiero referir en este ensayo. No pretendo introducir alguna teoría, sino llamar la atención de los iusinternacional privatistas a temas relacionados con la atribución de significados, la creación de significados y la participación dinámica del juez, estudios que hasta ahora han sido desarrollados por los teóricos del derecho contemporáneos, sin que parezca se hubiesen reflejado en disciplinas particulares, como la del DIPr.

${ }^{4}$ Rolando Tamayo y Salmorán, Razonamiento y argumentación juridica, Instituto de Investigaciones Jurídicas, UNAM, México, 2003, pp. 135 y 136.

5 No debe confundirse la antinomia con el llamado conflicto de leyes. Mientras la primera supone normas contrarias o contradictorias en un sistema, el llamado conflicto de leyes está referido a las respuestas diversas que sistemas diferentes dan a un problema. La antinomia puede resolverse mediante alguno de los tres mecanismos conocidos: ley posterior sustituye a la anterior, ley especial sustituye a la general y ley superior sustituye a la inferior. Ninguna de estas soluciones es aplicable a los problemas de conflictos de leyes. 


\section{ENUNCIADOS JURÍDICOS QUE CARECEN DE SIGNIFICADO PREDETERMINADO}

Ya que este ensayo no va dirigido a los teóricos del derecho, sino a los dedicados al derecho internacional privado, quiero comenzar recordando algunos textos legislados cuyo significado no está implícito en la ley. Aludiré, primeramente, a algunos que tal vez no tengan una relación muy estrecha con el DIPr, pero que sin embargo me ayudarán en la explicación, al menos, para sensibilizar la afirmación de que los textos legislados requieren ser interpretados.

Cito, entre otros ejemplos de la legislación mexicana, los siguientes: moral pública ${ }^{6}$, justicia $^{7}$, resolver con justicia ${ }^{8}$, moralidad $^{9}$, notoria moralidad ${ }^{10}$, antecedentes de moralidad $^{11}$, usos bancarios ${ }^{12}$, doctrina religiosa ${ }^{13}$, costumbres ${ }^{14}$, usos y costumbres de los pueblos indígenas ${ }^{15}$, prácticas de convivencia ${ }^{16}$, lugares públicos acostumbrados $^{17}$, equidad ${ }^{18}$, equidad social ${ }^{19}$, tradiciones ${ }^{20}$, tradición intelectual $^{21}$, fama pública ${ }^{22}$, reglas de la sana crítica ${ }^{23}$, reglas de la lógica ${ }^{24}$, fallos en conciencia ${ }^{25}$, reglas deportivas ${ }^{26}$, etcétera.

6 Art. 3 de la Ley de Asociaciones Religiosas.

7 Art. 553 del CCFed.

8 Art. 1306 del Código de Comercio.

9 Arts. 175 de la Ley Federal del Trabajo y 444 del CCFed.

${ }^{10}$ Art. 125 de la Ley Orgánica de los Tribunales de Justicia del Fuero Común del D.F.

11 Art. 163 de la Ley Orgánica de los Tribunales de Justicia del Fuero Común del D.F.

12 Art. 4 de la Ley Federal de Instituciones de Crédito.

${ }^{13}$ Art. 6 de la Ley de Asociaciones Religiosas.

14 Arts. 1856, 2607, 2609, 2661, 2751, 2754, 2760 del CCFed, 280 del Código de Comercio, 596 del Código de Procedimientos Civiles del D.F. y 180 del Código de Procedimientos Penales del D.F.

15 Art. 4 de la Constitución Política de los EUA Mexicanos.

16 Art. 234 de la Ley del Seguro Social.

17 Art. 535 del Código de Procedimientos Civiles del D.F.

18 Arts. 14, fracc. V, del CCFed, 46 y 344 del Código de Procedimientos Civiles para el D.F.

19 Art. 25 de la Constitución Política de los EUA Mexicanos.

20 Arts. 2014 del Código Civil y 1274 del Código de Comercio.

21 Art. 98 Ley Federal de Derechos de Autor.

22 Art. 1274 del CCFed.

23 Art. 112 del Código de Procedimientos Civiles del D.F.

24 Art. 402 del Código de Procedimientos Civiles del D.F.

25 Arts. 628 del Código de Procedimientos Civiles del D.F. y 120 del Código Federal de Procedimientos Civiles.

26 Art. 23 de la Ley de Estímulos y Fomento al Deporte. 
Se trata de enunciados que no son como la regla matemática que establece que dos por dos siempre son cuatro; regla que se caracteriza porque el resultado siempre será igual (así lo fue ayer, ahora y lo será mañana) y que así será aquí y en cualquier otro lugar del mundo. Los enunciados jurídicos normativos tampoco son iguales a los propios de los juegos, pues, por ejemplo, la regla en el ajedrez que dice que el movimiento del alfil será diagonal o que el movimiento del rey sólo será a un espacio, no admite la introducción de criterios que moldeen su significado. Sus textos, al menos, no se matizan fuertemente con criterios de racionalidad.

En los enunciados jurídicos, como los listados líneas arriba (que, en la idea de Hart, serían de textura abierta), se hace necesario que participe el juez y contribuya asignándoles un significado que, incluso, puede variar en el tiempo y en el espacio o, incluso, entre juez y juez. Los significados de estas expresiones jurídicas, simplemente, no están predeterminados. Su textura produce diversidad de significados. Ambigüedad, para utilizar una palabra familiar.

Se trata de textos cuyo significado pueden producir controversia y cambiar con el tiempo y el espacio, respecto de los cuales cabe afirmar que los criterios de validez formal no auxilian a la precisión del significado. En fin, carecen de una significación predeterminada.

\section{TEXTOS CUYO SIGNIFICADO LE CORRESPONDE AL APLICADOR}

Creo conveniente recordar otros ejemplos de otros países en cuya legislación se introducen conductas cuyos contenidos no han sido significados por el legislador, ni previamente al caso concreto que trata de resolverse.

Citaré, primeramente, algunas disposiciones legisladas extranjeras que permiten la aplicación de un ordenamiento distinto (en realidad, un sistema distinto) al que pertenece la propia disposición legislada. En unos casos un sistema estatal se vincula con alguno religioso y, en otros, un ordenamiento estatal con el de otro Estado de la comunidad internacional.

El Código de las Transacciones Civiles de los Emiratos Árabes prescribe como derecho supletorio al derecho musulmán, "dando preferencia a las soluciones más apropiadas de la Escuela del Imam Malik y del Imam Ahmad Ibn-Hanbal y, en su defecto, a las de la Escuela del Imam Ash-Shafi'i y del Imam Abu-Hanifah, según el interés 
en cuestión» (Art. 1). Añade que el derecho musulmán «servirá de referencia para la comprensión, la interpretación y la exégesis del texto" (Art. 2). En términos muy semejantes tenemos al Código Civil de Jordania; al Código Civil de la República Yemenita; al Código Civil de las Transacciones Islámicas de Yemen del Norte, Antigua República Árabe Yemenita; al Código Civil de Yemen del Sur, Antigua República Democrática Popular del Yemen ${ }^{27}$, etcétera.

Aunque estas disposiciones legisladas remiten a disposiciones religiosas, es evidente que se trata de vinculaciones entre sistemas distintos, en los que el aplicador del ordenamiento estatal, por disposición de su norma de vinculación o de conflicto, como mejor se les conoce, (como la de los ejemplos), tiene que recurrir a un ordenamiento no estatal o extraño e interpretarlo. Interpretación que no es fácil, sobre todo porque se trata de sistemas con principios diferentes.

Así como esta vinculación producida entre un sistema estatal y uno religioso, también suelen presentarse vinculaciones entre sistemas estatales, que obligan al operador jurídico (generalmente así lo prescribe el derecho positivo) a tener que interpretar lo que otro sistema estatal prescribe.

Así ocurre, por ejemplo, en la Ley sobre Derecho Internacional Privado de Corea del Sur, que prescribe como derecho supletorio las "costumbres comerciales», sin que parezca importar que se trate de costumbres coreanas o extranjeras (Art. 28); la Ley Relativa a la Fuerza Obligatoria de las Leyes, los Actos Administrativos y los Tratados Diplomáticos, al Conflicto de Leyes en el Tiempo, a la Condición de los Extranjeros y a la Aplicación de las Leyes de la República Centroafricana establece como derecho supletorio «los principios generales del derecho y, en su caso, en las costumbres y tradiciones de las partes litigantes» (Art. 46); la Ley sobre el Derecho Internacional Privado de Corea del Sur establece como derecho supletorio las costumbres comerciales y, si no las hubiere, la ley civil (Art. 28); etcétera.

Algo semejante a lo prescrito en estos ordenamientos extranjeros se encuentra en el ordenamiento local, especialmente cuando el operador jurídico mexicano está obligado a aplicar una disposición jurídica establecida en un ordenamiento jurídico extranjero (por estar así vinculada por la norma de conflicto mexicana), pero previamen-

27 Este último prescribe como derecho supletorio a los principios generales del derecho, pero precisa que para la definición de estos se recurrirá a «la ideología dominante en la sociedad en el momento de la aplicación (de la ley), debiendo respetarse las bases del socialismo científico y "las Cartas de la Revolución Nacional Democrática» (Art. 5). 
te tiene que interpretar la disposición extranjera y, al hacerlo, tiene que atribuirle un significado.

La Ley General de Sociedades Mercantiles (art. 251), por ejemplo, admite el reconocimiento de una sociedad constituida en el extranjero conforme a su sistema, lo que plantea el problema de saber qué es una sociedad extranjera. El art. 1856 del CCFed prescribe que «el uso o la costumbre del país se tendrán en cuenta para interpretar las ambigüedades de los contratos». Pero ¿en qué consisten esos usos y costumbres? Se reconoce, al menos, que existen ambigüedades.

Hay otros ejemplos que se encuentran en algunas normas materiales mexicanas (no se trata de las normas de conflicto). Así ocurre, por ejemplo, en la Ley de Comercio Exterior, que exige tomar en cuenta las prácticas desleales del comercio internacional ${ }^{28}$, $\mathbf{u}$ otras leyes, que prescriben tomar en cuenta las sanas prácticas ${ }^{29}$, las prácticas de comercialización de bienes ${ }^{30}$, las prácticas fiduciarias ${ }^{31}$, las prácticas industriales ${ }^{32}$, las prácticas desleales del comercio internacional ${ }^{33}$, las prácticas internacionales ${ }^{34}$, las prácticas internacionalmente aceptadas ${ }^{35}$, las prácticas diplomáticas y consulares ${ }^{36}$, las prácticas del mercado ${ }^{37}$, etcétera.

Bastan estos ejemplos para percatarnos que el aplicador, al resolver un caso concreto, encontrará que el legislador no ha especificado cuál es el sentido de los textos a aplicar, ni estos tienen un significado inmanente o natural, pues no se explicita cuáles son los contenidos, es decir, no están predeterminados.

En fin, cuando un juez está obligado a aplicar una ley, recurriendo a alguno de los textos ejemplificados, se encontrará en el dilema de saber cuál es el significado que ha de llevar al caso concreto.

\section{INTERPRETACIÓN Y CREACIÓN NORMATIVA}

La interpretación corresponde a la representación o significado que se tiene de algún signo. La semántica, como disciplina, nos au-

${ }^{28}$ Art. 5 de la Ley de Comercio Exterior.

29 Art. 4 de la Ley de Instituciones de Crédito.

30 Art. 19 Ley Federal de Protección al Consumidor.

31 Art. 16 de la Ley Federal de Instituciones de Fianzas.

32 Art. 19 Ley Federal de Protección al Consumidor.

33 Art. 5 de la Ley de Comercio Exterior.

${ }^{34}$ Arts. 10 de la Ley de Comercio Exterior y 18 de la Ley General de Población.

35 Arts. 37 y 91 de la Ley de Comercio Exterior.

36 Art. 8 de la Ley del Servicio Exterior Mexicano.

37 Art. 103 de la Ley Federal de Instituciones de Fianzas. 
xilia a entender los significados de los signos empleados por el generador de una disposición estatal o no estatal, escrita o no escrita, directa o indirecta. Aunque el signo puede ser escrito, también los gestos y actitudes de una sociedad son signos y, también, pueden interpretarse. De esta manera no sólo interpretamos textos escritos, sino también realidades, como costumbres, tradiciones, actitudes religiosas, fenómenos sociales, etc. Objetos, todos los cuales, pueden ser objeto de atención de un internacionalista.

Varios abogados y jueces mexicanos ${ }^{38}$ piensan que la interpretación sólo puede derivarse de textos escritos y expedidos oficialmente por el Estado, pero, como lo explico, también cabe agregar los usos, costumbres, actitudes religiosas, así como otras manifestaciones sociales reconocidas como fuentes indirectas. Si no se recurre a esto, entonces la interpretación solo se reduce a un mero acto de voluntad.

En realidad, el desarrollo del tema de la interpretación no es nada fácil. Hoy, como nunca, las diferencias en torno al tema se han extremado y las teorías se han multiplicado ${ }^{39}$. Por ello dije, desde el inicio, que mi ensayo supone una toma de posición, toma de posición que también debe adoptar un intérprete.

Conviene recordar que, aun cuando el texto de una ley pueda ser el mismo en varios países (la misma grafía o signos), la verdad es que su interpretación no necesariamente es la misma. Por ejemplo, el art. 17 del CCFed, que alude a la lesión, se suele interpretar en México de manera restringidísima, a diferencia de Alemania, donde se le entiende en un sentido más amplio. Lo que, a este respecto va-

${ }^{38}$ La Suprema Corte de Justicia de la Nación piensa en descubrir lo que pensó el legislador al establecer que «los principios filosóficos del derecho y de la hermenéutica jurídica aconsejan que para descubrir el pensamiento del legislador, es necesario armonizar o concordar todos los artículos relativos a la cuestión que se trate de resolver para, en esa forma, conocer su naturaleza, sea para decidir entre los diferentes sentidos que la letra de la ley puede ofrecer, sea para limitar la disposición, o bien, al contrario, para extenderla a los casos que el legislador parece haber olvidado, pero que se hallen evidenciados, supuesto que el órgano legislativo regula de modo general, mediante las leyes que expide, el conjunto habitual de situaciones jurídicas y delega en el juzgador la facultad de encajar los casos imprevistos dentro de esas normas generales, valiéndose para ello de los procedimientos de la analogía o la inducción, o del criterio existente dentro de las convicciones sociales que integran y orientan el orden jurídico vigente." AR 8179/43, 5a. época, t. LXXXIX, p. 5083. En sentido similar: Queja 93/89, Tercer Colegiado en Materia Administrativa del Primer Circuito, SJF, 8a. época, t. III, 2da parte-2, p. 573La Suprema Cotre ha sostenido al efecto que «los principiosL.

${ }^{39}$ Un esquema de las teorías puede verse en José Francisco Ursúa, «Interpretación jurídica: una propuesta de esquematización de planteamientos», Isonomía, Núm. 20, abril 2004, México. 
ria no es la definición de diccionario, sino la realidad social y valores sobre los cuales se aplica la disposición ${ }^{40}$. Esto es, lo que trato de afirmar es que en la interpretación operan las realidades del lugar, los valores y principios imperantes. De esta manera, cuando el juez interpreta, le da contenido al texto interpretado, en realidad, al texto creado.

Ya varios juristas le han dedicado algunas páginas a este problema. Kelsen, entre otros, implicaba la creación normativa en cada peldaño de la pirámide jurídica.

Ahora bien, aquí hay que hacer un agregado a lo que normalmente ven los teóricos de la interpretación jurídica, que parecen suponer un solo sistema. En la interpretación el juez no solo ha de preocuparse por interpretar los textos establecidos en su propio sistema, sino también los textos y signos extranjeros cuando la norma de conflicto de su sistema los vincula. Esto es, si una norma de conflicto del foro admite la aplicabilidad de un texto extranjero, este es válido acorde a la norma conflictual del propio foro y, posiblemente porque deriva del sistema extranjero.

Veamos, vamos a suponer que la norma de conflicto (NC) prescribe que la respuesta a la regulación del supuesto normativo se encuentra en alguna disposición del sistema extranjero (SE). De esta forma, la resolución del juez (RJ) es válida mediante un encadenamiento que se esquematiza como

$$
\mathrm{NC} \rightarrow \mathrm{SE} \rightarrow \mathrm{RJ}
$$

De donde NC y SE pertenecen a sistemas jurídicos diferentes, pero la validez en el foro de SE, deriva de NC. Así, cuando el operador jurídico va a aplicar una SE, tiene que interpretarla, creando la respuesta $(\mathrm{RJ})$.

Esta actividad (la creación de RJ) ha sido explicada, al menos, con dos tipos de criterios: el formal o cognitivo y el material, también conocidos, en la nomenclatura de Ferrajoli, como criterios de legalidad formal y material y corresponden, en cierta forma, con las teorías cognitivas y escépticas sobre la interpretación.

40 Boris Kozolchyk presenta un estudio interesante consistente en explicar lo qué ha de entenderse por "justo y equitativo", encontrando que aunque la literalidad de los textos pueda ser igual, la realidad social lleva a diferentes interpretaciones. Boris Kozolchyk, El derecho comercial ante el libre comercio y el desarrollo económico, McGraw Hill, México, 1996, pp. 137 y ss. 


\section{A) CRITERIOS FORMALISTICOS Y COGNITIVOS ${ }^{41}$}

Desde hace ya bastante tiempo en México, varios abogados, jueces, incluso profesores, suelen afirmar que interpretar consiste en desentrañar o descubrir el sentido de la ley, así como afirmar que el juez solo es un medio para llevar a la ejecución lo que ya ha resuelto el legislador ${ }^{42}$. Esta manera de explicar la interpretación encaja en la teoría cognitiva.

La teoría cognitiva supone que los textos a aplicar tienen un significado inmanente. Su intérprete solo tiene que descubrirlo. El juez que dicta RJ solo desentraña el sentido de lo que SE dice debe proceder. Algo así como que el contenido de RJ ya está implícito en SE.

En el caso de que una norma de conflicto designe como aplicable a un ordenamiento extranjero se presenta el problema de saber a qué recurrir para lograr la significación de ese texto extranjero (SE), pues (acorde a este enfoque), es necesario «descubrir» su significado. En cierta forma, siguiendo esta idea, Jurgen Samtleben explica que ${ }^{43}$.

«el juez no debe limitarse al mero texto legal. Antes bien, ha de tomar también en consideración las reglas de interpretación extranjeras. Además, ha de recurrir a la doctrina y especialmente a la jurisprudencia del país de que se trate en la misma medida en que lo haría un juez extranjero. Ha de emitir su propia opinión sobre cuestiones discutidas o no dilucidadas en el derecho extranjero" ${ }^{44}$.

La respuesta de Samtleben, aunque mecánica y formal, propone seguir una interpretación acorde a la técnica seguida en el extranjero, verificando, prácticamente el sentido que tiene en el extranjero. Así como en esta posibilidad, de recurrir a un ordenamiento vigente en el extranjero, hay otras en los que es necesario interpretar un ordena-

41 Aunque pueden atisbarse diferencias entre ambos criterios o teorías, me referiré a ambos en un solo epígrafe. En general, han ido de la mano. Guastini las examina en un solo apartado, Riccardo Guastini, Estudios sobre la interpretación jurídica, Porrúa, México, 2000 , pp. 13 y ss.

42 La prensa está llena de declaraciones de jueces que dicen «así lo resolví porque eso es lo que dice la ley o lo que dice el legislador".

${ }^{43}$ No es frecuente encontrar estudios sobre interpretación entre los internacional privatistas. Enseguida me refiero a dos, que no quiere decir que sean los más destacados en el tema interpretativo. Lo único que me interesa es destacar que la idea que presentan que es similar a la seguida por otros.

44 Jurgen Samtleben, «La aplicación de la ley extranjera en América Latina y en la República Federal de Alemania», Primer Seminario Nacional de Derecho Internacional Privado, Memoria, UNAM, México, 1979, pp. 237 y 238. 
miento extranjero aun cuando ya no esté en vigor o el Estado ya se hubiese fusionado con otro, como lo explica François Rigaux.

«[L]os casos más agudos son aquellos en que una misma fuente jurídica formal ha continuado rigiendo en varios países después de su secesión, recibiendo interpretaciones diferentes por parte de sus respectivas jurisprudencias. Cuando el juez de uno de esos Estados aplica la disposición común a título de ley de otro Estado, debe interpretarla con la jurisprudencia que se le ha incorporado en ese país. Así, para determinar la validez de un testamento ológrafo sometido a la ley belga, el Tribunal de Douai interpretó el artículo 970 del Código civil como lo había hecho el Tribunal de casación de Bélgica, que, en este punto, se separa de la interpretación francesa ${ }^{45}$.

Tanto Samtleben como Rigaux presuponen un enfoque externo o diferente al que normalmente está acostumbrado el juez que aplica la disposición extranjera. Ninguno de ambos juristas aclara qué es lo que materialmente debe contener el dato interpretado, aunque presuponen que se trata de descubrir o verificar su significado. Como se advierte, ambos criterios solo se quedan en un aspecto formalista y cognitivo $^{46}$. Tan mecánico como la gráfica de flujo que líneas arriba cite.

Desde esta óptica, la interpretación en el Derecho internacional privado ofrece varios problemas no fáciles de resolver, ya que el intérprete no solo se enfrenta a tener que aplicar una disposición de derecho positivo extranjero o recurrir a sus doctrinas o costumbres, sino también al problema que se presenta cuando el texto del ordenamiento a aplicar no ha sido significado previamente, esto es, que carece de una significación previa, que no ha dado su legislador, ni algún otro juez.

Comienzo por recordar que aunque el legislador extranjero establece un texto con el que pretende prescribir una conducta a seguir (o, incluso, remite a costumbres, usos, reglas religiosas), el hecho es que esa conducta no la define previamente al momento en que el juez la lleva al caso concreto. Incluso, en el caso de la llamada interpretación auténtica, puede ocurrir en que, aun cuando exista, sus términos sean contradictorios o que la disposición ya no sea aplicable. Por ello, lo que el juez tiene que definir es el contenido de la resolución que pronunciará (la RJ) (generalmente un texto). El juez debe

${ }^{45}$ François Rigaux, Derecho internacional privado, Civitas, Madrid, 1985, p. 337.

46 Además de la posibilidad de que el significado se descubra, cabe agregar la posibilidad de acertar en el significado. Se recurre al acertamiento, como lo evidencia Adrián Renteria al presentar algunos autores cognitivos. Opus supra cit, p. 49. 
recurrir a algún mecanismo para dotarle de contenido a la $R J$, mecanismo en el que cabría la posibilidad de recurrir a precedentes judiciales que ya le asignaron algún significado (subsistiendo el problema de la interpretación), aunque también cabría la posibilidad de que esos precedentes judiciales extranjeros no existan o que, aun existiendo, sean contradictorios.

Si una ley carente de significado pre-definido es extranjera, el juez doméstico deberá emplear los medios necesarios para atribuirle contenido. ¿Pero, cómo dotarle de contenido? Si el juez mexicano desea conocer ciertas prácticas comerciales griegas ¿qué hará para saber en concreto cuáles son esas prácticas?, ¿cómo las definirá?

$\mathrm{Al}$ revisar nuestros precedentes judiciales encontramos que en algunas ocasiones nuestros jueces han citado la aplicabilidad de estos e, incluso, parecen aplicarlos, pero, por desgracia, tampoco aparece descrito en las publicaciones oficiales lo que se ha hecho para interpretarlos, ni el significado que se les atribuyó. En alguna investigación que realice encontré que los jueces han aludido a las costumbres en el caso de marcas, prácticas desleales, usos mercantiles, usos y costumbres de la industria o comercio, usos honestos en materia industrial, prácticas comerciales, etc., pero, en ningún caso estas realidades fueron definidas (ni el procedimiento, ni su resultado), ni por el legislador (lo que no debe de extrañar), ni por el juzgador (cuando menos en la publicación oficial) ${ }^{47}$.

Acorde a esta explicación formalista solo llegamos a saber que la disposición de SE será la aplicable, pero la teoría no nos explica cuál es el contenido de la RJ, ni cómo es que en SE ya se encuentra el contenido de lo que se va a resolver. Si la SE indica que en las relaciones entre comerciantes debe seguirse un criterio de "moralidad mercantil», ¿cuál es el contenido que ha de ser llevado a la RJ?

\section{B) CRITERIOS MATERIALES O ESCÉPTICOS E INTERMEDIOS}

Las teorías materiales no rechazan el flujo a que se refiere la teoría formalista ( $\mathrm{NC} \rightarrow \mathrm{SE} \rightarrow \mathrm{RJ}$ ). Lo que ocurre es que no se quiere quedar con la mera explicación formal. Esta corriente tiene dos vertientes. La vertiente escéptica sostiene que la SE deja al intérprete sin

47 Jorge Alberto Silva, Derecho internacional privado, su recepción judicial, Porrúa, México, 1999, p. 217. 
saber que es lo que exactamente contiene SE. Sus seguidores son escépticos, por lo que al momento de tener que tomar la decisión (la $\mathrm{RJ}$ ), prácticamente tendrá el contenido que se le antoje al operador. La otra vertiente, la vertiente intermedia, estima que el contenido de SE se puede determinar recurriendo a los contenidos que se encuentran dentro de los parámetros del que deriva la SE. Supone que SE está inserta en un sistema que permite darle sentido a cualquier disposición.

Una respuesta propia del razonamiento práctico (que acoge la teoría intermedia) indica que cuando una norma de conflicto remite a un ordenamiento extranjero que, a su vez, se refiere a comportamientos que se producen en una realidad o para un grupo social diferente del juzgador, el texto de la disposición extranjera (y aquí sigo un criterio de razonabilidad) suele significarse tomando en cuenta criterios de realidad y valores, en general, la cultura jurídica a que pertenece el ordenamiento designado como aplicable. Se trata, de una propuesta diferente que no se queda con meros criterios formales o mecánicos. De hecho, bajo la concepción de esta perspectiva, el jurista no obra como autómata, sino que se compromete, toma partido. Lo que se hace patente debido a la indeterminación de los textos.

Mientras en el enfoque formalista la interpretación y la creación son capítulos o aspectos diferentes, en el enfoque material, ambos aspectos se fusionan. En otras épocas interpretación y creación normativa habían sido entendidas con significaciones diferentes, incluso, que cada una correspondía a órganos diferentes, esto no suele ser admitido en la actualidad como adelante se constatará.

Aunque uno de los criterios materiales (el escéptico) pudiera tender a afirmar la indeterminación total de SE, el criterio intermedio no solo ve la posibilidad de establecer los contenidos, sino que los crea dentro de ciertos delimitantes. De cualquier forma, ambas decisiones (escépticas o intermedias) tienen en común que el juez tiene que poner algo de su parte para dotarle de contenido a la SE (de aquí que los anote como criterios materiales).

Durante el siglo XIX se afirmaba que la creación normativa le correspondía al legislador, mientras que la interpretación, al juzgador, lo que, para el razonamiento práctico, es totalmente incorrecto. Un juez no solo interpreta, sino que también crea el contenido del texto creado (al menos conforme a los criterios materiales) y, con ello, la norma que resuelve el caso. Esto se entiende fácilmente cuando pensamos, por ejemplo, en el caso del juez que al dictar sentencia 
está creando la norma particular que soluciona el caso concreto. Es decir, no solo interpreta SE, sino que también crea la respuesta jurídica (RJ). Esto significa que, al menos para el juez, interpretar y crear son aspecto íntimamente unidos y, en cierta forma, fundidos.

Si un juez obligado a aplicar una costumbre extranjera respecto de la cual encuentra que una persona (el actor) la caracteriza como a $+\mathrm{b}+\mathrm{c}$, mientras que otra (el demandado) la caracteriza como d + e $+\mathrm{f}$, el juez no solo afirmará tomar en cuenta una costumbre extranjera sino que esta consiste en la primera o segunda caracterización o, acaso, en una tercera. El hecho es que no está predeterminada. Al decidirse por una respuesta, eso no quiere decir que solo la escoja,

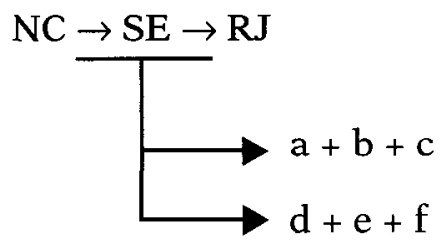
sino que la crea.

Conforme a esta perspectiva no basta que el juez afirme que $\mathrm{X}$ es equitativo, sino que hay que decir en qué consiste lo equitativo, dándole contenido a la resolución.

En este criterio material, encaminado a aplicar una disposición extranjera, el juez pasa a identificar el texto extranjero, a interpretarlo y a crear la disposición jurídica aplicable, para luego ordenar o proceder a su ejecución. De todo esto, de momento, llamaré la atención a la interpretación y creación normativa ${ }^{48}$.

Mediante la interpretación, acorde a este criterio material (en cualquiera de sus vertientes), el juez le atribuye un significado a una expresión y, al atribuirlo, crea el contenido del texto; es decir, no lo descubre, ni supone que ese significado es inmanente o connatural a la expresión o que ese significado es preexistente al momento de resolver (como lo pudiera sugerir o afirmar algún enfoque cognitivo o formalista). Simplemente, el contenido establecido por el juez es un significado que ha estimado idóneo, por lo que, al adoptarlo como válido, ese significado resuelve el caso planteado.

Si la ley dice que se debe resolver con equidad, el juez, al aplicarla, resolverá que es equitativa aquella conducta caracterizada por a + b + c. Es decir, en la toma de la decisión llenará el contenido, creando la respuesta.

Para que el juez adopte el significado de una expresión lingüística o una costumbre extranjera no es necesario que exista un significado

${ }^{48}$ No quiero decir con esto que la interpretación solo sea mero procedimiento, ya que también incluye al resultado. 
previo. Si el juez estima que el significado que él ha elaborado es al que responde la expresión lingüística o la costumbre, la norma ha sido creada. Ocurre lo mismo cuando opta por el significado que le propone el actor o el demandado, pues al optar se decide y elige y su decisión ya no es la de un particular, sino una decisión jurídica.

En los casos de la interpretación analógica se ve más claro que el juez no solo se le atribuye significado a un texto, sino que el nuevo implica un contenido nuevo, creado.

En fin, acorde a este enfoque material, la interpretación y la creación normativa se funden (generalmente). Ni la interpretación responde a una idea cognitiva, ni la creación es algo ajeno al juez.

\section{INTERPRETACIÓN Y CREACIÓN EN EL DERECHO INTERNACIONAL PRIVADO}

Si la interpretación de los textos domésticos causa problema, con mayor razón los extranjeros. En cuanto a los locales, Riccardo Guastini se plantea el caso del art. 10 de la Constitución italiana, que prescribe que el ordenamiento italiano se integra por las «normas de derecho internacional generalmente reconocidas», luego se cuestiona ¿cuáles son esas normas generalmente reconocidas?, punto con el que pone en aprietos al intérprete ${ }^{49}$. Algo similar nos podemos cuestionar acerca de lo que pueda significar en México las «reglas reconocidas en la esfera internacional» a que alude nuestro Código Federal de Procedimientos Civiles ${ }^{50}$.

Al operador del derecho (juez, notario, funcionario, etc.) que está obligado a aplicar una disposición local con vocación internacional o un ordenamiento extranjero, debe entender (y llevar al plano real) los contenidos establecidos en el sistema a que pertenece el ordenamiento correspondiente, lo que supone reconocer (según el criterio intermedio) diversas manifestaciones sociales, valores, principios, derechos constitucionales, etc. Mientras las teorías escépticas de la

49 Riccardo Guastini, «Problemas de interpretación», Doxa, Alicante, Núm. 4, 1987, p. 122. El mismo ejemplo en Riccardo Guastini, Estudios sobre la interpretación jurídica, Porrúa, México, 2000, p. 59.

50 Art. 571, «Las sentencias, laudos arbitrales privados de carácter no comercial y resoluciones jurisdiccionales dictados en el extranjero, podrán tener fuerza de ejecución si cumplen con las siguientes condiciones: [...] III. Que el juez o tribunal sentenciador haya tenido competencia para conocer y juzgar el asunto de acuerdo con las reglas reconocidas en la esfera internacional que sean compatibles con las adoptadas por este Código". 
interpretación podrían llevar a asignarle cualquier contenido al texto extranjero, en las intermedias se suelen acoger ciertos criterios, como los materiales que acabo de mencionar. En consecuencia, el aplicador de un ordenamiento jurídico extranjero no podrá resolver un caso concreto creando y aplicando una conducta diferente a la prescrita en el sistema designado como aplicable. Una disposición que obligue a resolver conforme a la equidad, el producto de tradiciones o disposiciones religiosas, debe interpretarse de manera que no contradiga ostensiblemente los criterios de razonabilidad derivados del sistema a que pertenece el texto designado como aplicable; de otra manera se estaría aplicando otra cosa.

Sin duda alguna esta técnica de interpretar siguiendo criterios y técnicas extranjeras es una toma de posición, reflejada en la mayoría de los textos positivos de cada uno de los Estados y de tratados internacionales.

En la interpretación de textos (o signos) jurídicos diferentes al doméstico, se suele recurrir a exigir que en la labor de interpretación se sigan los mismos métodos o prácticas seguidos en el extranjero (interpretación lex causae) y no los propios. Se trata de una idea derivada de los criterios intermedios. Acogiendo en cierta forma esta idea, Eduardo Trigueros afirmaba que en el caso de que un tribunal extranjero ya hubiese interpretado un texto religioso, las costumbres comerciales imperantes o cualquier disposición no estatal, la interpretación lex causae deberá ser la observada por el juez mexica$\mathrm{no}^{51}$. Claro que esta opinión presupone un criterio judicial previo que, por otra parte, no necesariamente tiene que ser acogido, a menos que el criterio judicial extranjero vincule a decisiones futuras, lo que no es muy común ${ }^{52}$.

Mi afirmación, acogida en la mayoría de los sistemas de la comunidad internacional (apoyados en criterios intermedios), me lleva a afirmar que para interpretar cualquier disposición designada como aplicable, en especial, la que se refiere a manifestaciones sociales no escritas, cabe la posibilidad de tomar en cuenta la cultura, ideología y filosofía del lugar o grupo donde se presenta esa manifestación. Lo anterior tiene una explicación. Si lo que se va a aplicar es un texto jurídico extranjero, lo menos que puede hacerse consiste en apegarse al

${ }^{51}$ Eduardo Trigueros Sarabia, Estudios de derecho internacional privado, UNAM, Instituto de Investigaciones Jurídicas, México, 1980, p. 239.

$52 \mathrm{Ni}$ siquiera en México una decisión judicial vincula salvo que se «siente jurisprudencia», esto es, que se produzca un específico número de casos y se siga un procedimiento especial. 
sentido que en el extranjero se le pudiera atribuir, pues este es parte de su sistema. Con esto se evita la arbitrariedad en la interpretación y se establecen marcos o límites para la atribución de significados. Luego entonces, el significado no resulta tan indeterminado, si hacemos a un lado la teoría escéptica.

El intérprete, que sigue una norma de conflicto, y que por razón el texto está vinculado a una manifestación social de cualquier lugar o grupo social del que provenga, debe interiorizarse en el conocimiento de la relación, fenómeno o contexto social dentro del que se genera el caso planteado. Esto es, debe procurar conocer las relaciones o situaciones sociales que ahí se generan y practican; debe realizar un estudio sociológico, antropológico e, incluso, sobre los valores imperantes en el lugar o grupo, cuyo ordenamiento será el aplicable; debe introducirse en el conocimiento del léxico sobre el que se asienta el conjunto normativo, en especial, cuando sus disposiciones han sido escritas. No hay que olvidar que el sentido del lenguaje vale para un lugar y tiempo específico ${ }^{53}$. Hacerlo de otra manera solo nos llevaría una interpretación que pudiera llegar a lo arbitraria, que solo sería acogida por la teoría escéptica.

El intérprete del derecho extranjero ha de recurrir a criterios materiales que identifiquen su contenido, por lo que, al momento de definirlo, crea la norma. Creación que se produce no solo bajo un esquema formal, pues es necesario que siga los lineamientos de un razonamiento práctico y no solo teórico.

Por otro lado, no solo los textos extranjeros producen problemas al intérprete. También los textos domésticos, por lo que, en algunos casos, cabría recurrir a técnicas interpretativas correctoras, esto es, recurriendo a argumentos que rechazan textos absurdos o fuera de época si se siguiera un significado literal. En este caso, expresa Guastini, se apela a una «supuesta naturaleza de las cosas, dadas las variaciones en el tiempo" ${ }^{54}$. Pondré como ejemplo la disposición del Código de procedimientos civiles de algunas entidades federativas, que prescriben que el plazo para contestar una demanda, tratándose de personas notificadas en el extranjero, será de un día más por cada 40 kilómetros de distancia. Si se hiciera una interpretación literal del texto, resultaría que una persona que resida en Madrid o en

53 Incluso, ni siquiera es fácil saber qué significa interpretación literal o significado literal a que suelen recurrir algunos códigos. Tecla Mazzarese, «Interpretación literal: juristas y lingüistas frente a frente», Doxa, Alicante, Núm. 21, 1998.

54 Riccardo Guastini, Estudios sobre la interpretación jurídica, Porrúa, México, 2000, p. 33. 
Milán gozaría de años para contestar. Una interpretación razonable diría que el legislador tomó en cuenta ese plazo pensando que era la distancia que por día podía recorrer un caballo, siendo absurdo pensar que se podría ir a caballo desde México hasta Europa.

\section{INTERPRETACIÓN, CALIFICACIÓN Y APLICACIÓN DEL DERECHO EXTRANJERO}

Al juez interesado en el derecho internacional privado no solo le interesan los problemas relacionados con la interpretación de un texto (incluso un signo) extranjero, sino también aquellos en los que ha de calificar un supuesto fáctico, lo que ha de hacer (y así se suele sugerir en las leyes) acorde a las prácticas seguidas en el extranjero.

Mediante la calificación (y aquí me detengo para hacer un breve recordatorio de lo que es) se quiere significar que una conducta o supuesto fáctico se subsume dentro del significado de una expresión jurídica, siempre y cuando la interpretación del dato encaje o encuadre en descripción normativa, que también tiene que ser interpretada (luego, la interpretación no está referida solo a textos, sino también a datos fácticos que tienen un encuadre o calificación jurídica). En breve, calificar es subsumir el supuesto de hecho en el supuesto o descriptor acogido por una disposición jurídica.

Mediante la calificación de un supuesto fáctico (quaestio facti) se comprende el papel o sentido que una conducta o acción significa jurídicamente (quaestio iuris). Este encuadramiento se realiza mediante un mecanismo intelectual que se inicia con la interpretación del dato fáctico al que se le otorga un significado, mismo que al ser contrastado con un descriptor legal se le subsume en este. El hecho de subsumir, significa adoptar una posición y, con ello, optar por una respuesta.

Presentaré un ejemplo. Una pareja de casados en Navarra, España, conviene en que los bienes que se adquieran durante el matrimonio serán de ambos cónyuges, pero que, al fallecer uno de ellos, los bienes pasarán a los hijos que procrearen. En este caso, ¿la cláusula que deja los bienes a los hijos encaja como cláusula contractual o como cláusula testamentaria?, ¿se califica como contrato o como testamento?, ¿cómo calificará un juez mexicano a esta cláusula?

Para responder, hay que tomar en cuenta que el sentido del quehacer fáctico sólo puede entenderse dentro de una cultura jurídica específica. Si el testamento puede incluir las disposiciones de bienes 
para después de la muerte, ¿qué tanto influye que esa disposición se haga en las capitulaciones patrimoniales del matrimonio en forma simultáneamente por ambos cónyuges? Se le denomina de una manera y encuadra en un concepto o descriptor normativo específico. En esta labor de encuadramiento está interesado el intérprete, pues la calificación se nutre en multitud de sentidos semánticos en los que influye la sociología, la antropología o la cultura jurídica. Es el dato de la vida real al que se le atribuye un sentido jurídico. Obviamente, en esto se interesa el juez, que al calificar, crea la respuesta concreta, esto es, define hasta donde vale admitir como testamento una disposición sobre bienes para después de la muerte.

La calificación de un supuesto fáctico no es universal (no es igual para los operadores de cualquier lugar del mundo), tampoco es intrínseca (su significado tampoco es propio del elemento lexical), ni está predeterminada. El significado de lo que un testamento pueda ser, así como si un dato fáctico encuadra o no en la noción de testamento supone una acción intelectual. Lo mismo ocurre con la prescripción de un derecho. Por ejemplo, en EUA, a la prescripción se le califica en el derecho procesal, mientras que para la mayoría de los países de la familia romano-germánica, en el derecho sustantivo. Suponemos, por tanto, que mediante la calificación se adopta un criterio calificador, esto es, definidor. Normalmente el derecho positivo se involucra en una toma de posición política (obliga a ponerse sobre los zapatos del juez extranjero).

Además de interpretar y calificar «de la misma manera como lo haría un juez extranjero" (incluso cuando se trata de disposiciones no escritas), el juez mexicano aplicará el texto interpretado tal y como lo haría un juez extranjero. ${ }^{55}$ En este sentido, la interpretación, la calificación y la aplicación, que vengo mencionando, se uniforman evitando la diversificación de criterios materiales con el fin de unificar el tratamiento (principio de uniformidad). Esto es, el juez mexicano deberá ponerse sobre las botas del juez extranjero al interpretar, calificar y aplicar un sistema extranjero.

No hay que olvidar que la aplicación no solo se produce después de que se crea la norma (se interpreta y califica), como algunas teorías antiguas lo sostuvieron, sino también que la creación se produce cuando se observa el problema a partir de la norma superior o la de

${ }^{55}$ Art. 14 CCFed. «En la aplicación del derecho extranjero se observará lo siguiente: I. Se aplicará como lo haría el juez extranjero correspondiente, para lo cual el juez podrá allegarse la información necesaria acerca del texto, vigencia, sentido y alcance legal de dicho derecho". 
reconocimiento que le imprime un criterio de validez a la norma creada (validez formal y material) ${ }^{56}$. La aplicación no solo supone que se parte de, sino también que se llega $a$. De esta manera, cuando un juez mexicano toma en cuenta la disposición extranjera la aplica, creando una inferior. De esta forma, aplicación y creación también se funden (en algunas ocasiones) en un solo momento intelectual, aunque esto no quiere decir que se trate de lo mismo. Guastini, por ejemplo, admite que los particulares pueden interpretar, pero no aplicar ${ }^{57}$.

\section{LA ARGUMENTACIÓN COMO UN MEDIO PARA DEFINIR SIGNIFICADOS}

Como lo vengo explicando, desde no hace mucho tiempo se ha recurrido a considerar la interpretación desde una perspectiva material, la que solo se entiende a partir de la argumentación, cuya teoría, bastante desconocida en las obras clásicas de DIPr, me lleva a resumir algunas explicaciones previas en las que rápidamente me detendré. Adelanto que la argumentación no supone el enfoque del jurista tradicional de laboratorio, que recurre al razonamiento teórico (con un mos academicus), sino el del juez que tiene frente a sí un caso concreto y tiene que recurrir al razonamiento práctico (con un mos forensis).

Para definir al significante se suele asumir una posición política, acogiendo el criterio intermedio a que ya me referí. Normalmente el intérprete se introduce en el texto del sistema, pero no solo bajo una perspectiva analítica, sino que recurre a todo el sistema, pues cree firmemente que solo dentro de este podrá dar un significado contextual, para lo cual ha de comenzar problematizando todos los significados posibles, hasta encontrar un criterio justificativo. Vamos, desde esta posición no es posible saber cómo es el árbol de un bos-

56 Manuel Atienza, Las razones del derecho, teorías de la argumentación jurídica, Centro de Estudios Constitucionales, Madrid, 1992, p. 32. La aplicación del derecho, afirma Rolando Tamayo y Salmorán, siguiendo un criterio formal, «es una función regular del orden jurídico; a través de ella los órganos aplicadores (tribunales, autoridades administrativas, etcétera), en ejercicio de sus facultades, determinan que un cierto caso concreto del tipo definido en la norma general se ha presentado y como consecuencia de ello, efectúan un acto por el cual actualizan las consecuencias previstas.» Rolando Tamayo y Salmorán, Elementos para una teoría general del derecho, Themis, México, 1996, pp. 171 y ss.

57 Riccardo Guastini, Estudios sobre la interpretación jurídica, Porrúa, México, 2000 , p. 9. 
que con solo verlo desde el aire, es necesario caminar a su alrededor, ver los árboles y hierbas que lo rodean, para percibir y conocer no solo el árbol, sino también el bosque, es decir, es necesario explorar. No se puede conocer el árbol por sí solo, si no se toma en cuenta el lugar a que pertenece. Solo así se sabrá por qué el árbol vive y se nutre.

La argumentación, en términos sencillos, se corresponde con un discurso que presenta una tesis razonada que le da respuesta a un problema específico (interpreta y le da significado a un texto). Por lo general, se recurre a esta, cuando las respuestas a un problema suelen ser debatidas, lo que ocurre con frecuencia cuando se presentan por los interesados varias significaciones.

En el caso del juez, no basta que elija cualquier significación que se le presente o cualquiera que crea conveniente (como pudiera ocurrir en una teoría escéptica). Tampoco basta que la tesis expuesta solo convenza o que solo logre que el estado de ánimo del destinatario se incline por esa respuesta. Es necesario que las razones, las buenas razones, no dejen duda respecto a la respuesta elegida, esto es, el contenido de la norma creada. Como explica Manuel Atienza ${ }^{58}$, la argumentación permite "operar con sentido en el derecho», lo que, además, es parte de la cultura jurídica en la que se desarrolla el texto a interpretar. Luego, la argumentación no se reduce a actitudes formales o mecánicas. Al final, argumentar-interpretar, como expresa Adrián Renteria Díaz, significa resolver ${ }^{59} \mathrm{y}$, al resolver, hay una toma de posición.

Con frecuencia suele confundirse a la argumentación con otras cosas o actividades. Una diferencia entre la retórica y la argumentación consiste en que en esta última la respuesta es razonada y justificativa, no se conforma con solo convencer. Tampoco basta acumular argumentos para un específico auditorio ${ }^{60}$. Ni basta que el abogado defensor conmueva al jurado que juzga al acusado. Un argumento supone la ponderación de las respuestas posibles y sobre la base de un buen razonamiento se elige el que responde al contexto del sistema jurídico.

La argumentación tampoco debe confundirse con la lógica, especialmente con la lógica formal. Mientras en esta podemos presuponer

58 Manuel Atienza, El derecho como argumentación, Fontamara, México, 2004.

59 Adrián Renteria, opus supra cit., p. 54.

60 Rolando Tamayo y Salmorán, Razonamiento y argumentación jurídica, Instituto de Investigaciones jurídicas, UNAM, México, 2003, p. 196. 
una premisa mayor, una menor y una conclusión, en la argumentación el método es diferente ${ }^{61}$. El argumento tampoco es una receta o solo un proceso para tomar decisiones, sino también las razones mismas, el discurso que justifica la toma de decisión. Justificación que no va solo para los litigantes, ni el superior, sino también para el público en general y para sí. Argumentar, tampoco es sinónimo de debatir ${ }^{62}$.

La argumentación no se queda en que el juez solo aplique la legislación, ni presupone que el derecho solo es un mecanismo instrumental, sino que implica, como necesario, justificar el sentido de la decisión (tomar en cuenta el aspecto material). La idea de que al derecho no le importan los valores y realidades (como fue expuesta por alguna tendencia positivista) no funciona desde esta perspectiva ${ }^{63}$. Es necesario llenar el contenido de lo que se va a resolver; es necesario revisar el aspecto material.

La argumentación está presente en la interpretación y en la calificación y le es importante al juez, al teórico, al abogado, a cualquier operador jurídico. Le es necesario para encontrar el contenido posible a un asunto controvertido pues de esto depende la toma de la decisión.

De igual forma, la argumentación funciona en un Estado de derecho en el que se aceptan principios democráticos (Habermas), se incluyan los derechos humanos (Ferrajoli) y se pueda apelar a principios de protección de estos mediante tribunales que garanticen el discurso y su efectividad. De otra forma, solo sería hablar en el desierto.

En fin, el problema que acarrea un examen reducido a solo el aspecto lingüístico o el meramente analítico no auxilia en nada para saber exactamente cuál es el sentido que habrá que dársele a frases y palabras establecidas en la ley. Sin la argumentación no se llena el sentido que ha de imprimírsele al derecho.

61 Un argumento puede apoyarse en diversas razones. Summers, por ejemplo, alude, entre otras, a razones sustantivas, autoritativas, fácticas, etcétera. Jaime Cárdenas Gracia, La argumentación como derecho, Instituto de Investigaciones Jurídicas, México, 2005, p. 24.

${ }^{62}$ Rolando Tamayo y Salmorán, Razonamiento y argumentación juridica, Instituto de Investigaciones jurídicas, UNAM, México, 2003, p. 197.

63 Para una teoría pura del derecho el derecho puede tener cualquier contenido, solo exige que responda a un criterio de validez formal. 


\section{LA ARGUMENTACIÓN EN EL DERECHO INTERNACIONAL PRIVADO}

Quien argumenta debe tener presente que ninguna significación de la ley está predeterminada, se tiene que crear. Para un seguidor de la Escuela de la Exégesis no cabría la posibilidad de pensar en argumentar. La argumentación supone un margen de discrecionalidad para la toma de la decisión como se advierten de las dos hipótesis que paso a referir y que se le pueden presentar a un juez mexicano.

En la primera, tomo en cuenta el art. 14 del $C C F e d$, que prohíbe aplicar derecho extranjero cuando sus disposiciones "o el resultado de su aplicación sean contrarios a principios o instituciones fundamentales del orden público mexicano». En esta disposición, la definición de "orden público" no se encuentra en el texto legislado, ni existe una definición o aclaración oficial del mismo, ni siquiera en los precedentes judiciales mexicanos. Es más, ni la doctrina se atreve a darle un significado. Es muy normal que se afirme que el orden público es cambiante y que puede responder a criterios de política, economía, sociales, religiosos, etcétera.

Supongamos que una persona ha contraído matrimonio en el extranjero con tres mujeres, sin disolver uno de ellos, algo que es posible en los países musulmanes. La ley mexicana prescribe que el matrimonio extranjero puede ser reconocido por las autoridades mexicanas ${ }^{64}$. Estando en México el marido pretende se le reconozca a sus tres cónyuges al amparo de esta disposición, pero el Ministerio público sostiene que (como aparece en el citado art. 14) no cabe ese reconocimiento pues sería contrario a los principios o instituciones fundamentales del orden público mexicano. En un caso como este, el juez se encuentra en la disyuntiva de reconocer o no ese matrimonio poligámico, pero para ello tiene que resolver previamente el significado de "orden público», pues del significado que se le atribuya a este enunciado depende la respuesta.

Ninguna ley indica o caracteriza qué ha de entenderse por orden público, ni existe una definición preconcebida para este caso, ni siquiera en los precedentes judiciales ${ }^{65}$, pero el juez tiene que resolver

${ }^{64}$ Art. 51 del $C C D F$ : «Para establecer el estado civil adquirido por los habitantes del Distrito Federal fuera de la República, serán bastantes las constancias que los interesados presenten de los actos relativos, sujetándose a lo previsto en el Código de Procedimientos Civiles, y siempre que se registren en la oficina del Distrito Federal que corresponda».

65 Aunque se han producido algunas sentencias la definición de orden público no está caracterizada. Jorge Alberto Silva, Derecho internacional privado, su recepción judicial, México, Porrúa, 199, pp. 183 y ss. 
el caso, como así lo ha resuelto la Suprema Corte de Justicia, la que ha sostenido que el juez debe definir al orden público ${ }^{66}$. Para esto, el interprete debe de recurrir a una serie de razonamientos, pues no basta que solo resuelva, ni que solo cite el texto legal en que se funda (fundamentación), ni que solo de algunos razonamientos de naturaleza formal (motivación) ${ }^{67}$. Es necesario que explique el porqué de su conclusión, esto es, que de razones de naturaleza material. Tal vez se le ocurra apoyarse en razones de moral local, de costumbres propias, de principios que sostienen los derechos constitucionales ${ }^{68}$, pero tiene que dar razones. Además, tiene que convencer y justificar con razonamientos, que tienen que encuadrar en el sistema (contextualizar la respuesta).

En la segunda hipótesis anunciada quiero referirme a la establecida en el art. 14, fracc. V, del CCFed ${ }^{69}$. Conforme a esta disposición cuando el juez advierta que un mismo supuesto fáctico está regulado por diversos ordenamientos, tiene que «aplicarlos armónicamente», "procurando realizar las finalidades perseguidas por cada uno de tales derechos». Como seguramente se encontrará con dificultades deberá resolverlas «tomando en cuenta las exigencias de la equidad en el caso concreto".

Aquí hay varias expresiones lingüísticas que careciendo de un significado previo son de textura abierta, tal es el caso de aplicación armónica, finalidades de cada sistema jurídico, equidad, etc. El significado de cada una de estas expresiones lingüísticas no puede ser obtenido recurriendo solamente a la lógica formal, ni empleando solo procedimientos deductivos, ni apegarse a lo que diga el diccionario.

66 Segunda Sala, Quinta época, T-XCVII, p. 142, Revisión del Incidente de Suspensión 2249/1948, Sec. 2a., Mijares y Hermano, 7 de julio de 1948, unanimidad de cuatro votos.

67 Mientras la motivación clásica solo se conforma con una demostración interna, carece de la externa, que para muchos es la justicia.

${ }^{68}$ Sobre el particular, Francesco Viola, expone que «la constitucionalización de los valores fundamentales en principios de derecho positivo es en sustancia una positivización de los finalidades fundamentales de las normas pertenecientes a un sistema jurídico dado».... esto "constituye un criterio para la actividad interpretativa». Francesco Viola, "Interpretación e indeterminación de la regla jurídica», Problemas contemporáneos de la filosofía del derecho, Enrique Cáceres et al (compiladores), Instituto de Investigaciones Jurídicas, México, 2005, p. 933.

69 "Cuando diversos aspectos de una misma relación jurídica estén regulados por diversos derechos, éstos serán aplicados armónicamente, procurando realizar las finalidades perseguidas por cada uno de tales derechos. Las dificultades causadas por la aplicación simultánea de tales derechos se resolverán tomando en cuenta las exigencias de la equidad en el caso concreto". 
En cualquiera de las hipótesis que se ponga sobre la mesa, el juez podrá tomar en cuenta la diversidad de soluciones existentes o posibles pero deberá elegir, no solo la más convincente, sino la más razonable, la que justifique la toma de la decisión; lo cual se logra tomando en cuenta el contexto del sistema, especialmente, los principios que derivan de la Constitución del Estado moderno, como es el caso de los derechos básicos del ser humano.

Casos como estos, que abundan en el DIPr, suelen ser catalogados como «casos difíciles» en la terminología de Ronald Dworkin, por lo que con mayor razón, se hace necesario recurrir a la argumentación. En un caso difícil, la interpretación no responde a criterios cognitivos o preconcebidos, de hecho, yo pensaría que se excluyen. La falta de certeza en la legislación, su ambigüedad y vaguedad es, precisamente, lo que lo hace difícil. Aunque en el caso fácil cabría la posibilidad de recurrir, en algunos momentos, a experiencias previas, sería un poco más difícil o dudoso en los casos difíciles.

No obstante, a decir de varios teóricos (como Hart), la interpretación (en cualquier caso) no es arbitraria, pues también sigue estándares que guían a una resolución razonada. La introducción de estos elementos supone una toma de posición.

No cualquier cosa es una razón, afirma Rolando Tamayo y Salmorán, para que sea una razón «tiene que satisfacer la regla de reconocimiento de razones ${ }^{70}$, circunscribirse a parámetros. De esta forma, el gobierno de México, cuando ha ratificado algunos tratados, ha introducido lo que llama declaraciones interpretativas, esto es, parámetros o estándares conforme a los cuales ha de hacerse una interpretación ${ }^{71}$.

La existencia de estos estándares son precisamente los que delimitan a una resolución razonada de una arbitraria. Si no existieran los delimitantes no cabría la posibilidad de hablar de responsabilidad judicial, como lo enfatiza, con gran detalle, Adrián Rentería ${ }^{72}$. La simple lógica deductiva no permite diferenciar a los argumentos validos de los manifiestamente inválidos ${ }^{73}$.

${ }^{70}$ Rolando Tamayo y Salmorán, Razonamiento y argumentación juridica, Instituto de Investigaciones jurídicas, UNAM, México, 2003, p. 202.

71 En este último caso se trata de razones para la acción.

72 Adrián Renteria, opus supra cit.

${ }^{73}$ Manuel Atienza, Las razones del derecho, teorias de la argumentación juridica, Centro de Estudios Constitucionales, Madrid, 1992, p 32. 
La posibilidad de crear el contenido de la norma no es extraña en los países del common law, ni tampoco en los de la familia romano-germánica, a pesar de que predomina el sistema legisla$\mathrm{do}^{74}$.

Es necesario tener presente que como el derecho suele expresarse mediante el lenguaje (aunque, no creo que todo sea lenguaje), lo que de por sí ya implica cierta ambigüedad y vaguedad en cada palabra, a la vez, en ocasiones, de esa vaguedad está conciente el legislador, quien introduce a propósito expresiones de textura abierta no solo para facultar (Hart) a los jueces a resolver el caso concreto, sino para obligarlos (Dworkin) ${ }^{75}$; cosa que estos deben de hacer, creando con ello la norma al caso concreto.

En fin, los iusinternacional privatistas se refieren, con frecuencia a la armonía material o a la armonía judicial. La comprensión de estas expresiones se advierte mejor cuando apelamos a la argumentación. Algo similar se debe hacer presente en los casos en que una disposición unilateral se bilateraliza o cuando se ha aceptado la norma de conflicto extranjera en los casos de reenvio o en los llamados subterfugios conflictuales ${ }^{76}$.

${ }^{74}$ John Henry Merryman apunta que esta posibilidad se ha venido reduciendo en los sistema romano-germánico y dando paso a una autoridad mas amplia de los jueces. Es a este fenómeno al que el le llama proceso de decodificación. Se ha pasado de un sistema legal monocéntrico a uno policéntrico. La inalterable autoridad de los legisladores - afirma - también se ha debilitado con el surgimiento del poder de los jueces que no solo interpretan a su manera una ley, sino que tienen también la facultad de revisarla y anularla. John Henry Merryman, "The future of the civil law tradition", en The civil law tradition: Europe, Latin America, and East Asia, Michie Company, Law Publishers, Virginia, 1994, pp. 1244 y 1245.

75 Yo recuerdo que un ambiente como este se respiraba cuando, en el seno del XII Seminario Nacional de Derecho Internacional Privado, 1988, al concretarse las reformas al CCFed se aludía al compromiso que debía tener el juez al momento de interpretar; se hablaba, incluso, de la «actitud abierta y receptiva».

${ }_{76}$ Denominación que emplea Friedrick K. Juenger para significar las tretas a que recurren algunos jueces para evitar la aplicación del ordenamiento designado por la norma de conflicto. Esta manipulación se advierte de la siguiente forma. Una vez que un litigante alega a su favor un ordenamiento designado por la norma de conflicto, la autoridad recurre a interpretaciones y manipulaciones para evitar la aplicación de ese derecho. Recurre de esta forma a otra calificación, al reenvío, a oponer la excepción de orden público, etc. El subterfugio no es la institución aplicada, sino el método utilizado para aplicarla. En el fondo, una técnica como esta debilita la armonía de soluciones y corrompe la argumentación jurídica. Friedrick K. Juenger, «Balance y perspectivas de la década en Estados Unidos», en Principios, objetivos y métodos del derecho internacional privado, perspectiva de una década, Centro de Estudios Superiores Sociales y Jurídicos Ramón Carande. Madrid, junio de 1993, p. 44. 


\section{A MANERA DE CONCLUSIÓN}

Al llegar al final de este ensayo, y no porque lo hubiese agotado (pues también me he brincado varias premisas), solo trataré de resumir alguna idea que sea útil para los ius internacional privatistas.

Destaco con todo lo anterior, que si un juez puede interpretar también puede atribuirle significados a las expresiones y, con ello, crear la norma que resuelve el caso concreto.

Por desgracia, nuestros jueces parecen tener miedo para afirmar que son creadores de normas jurídicas. Se esconden en el mito de que solo el legislador crea normas y que el juez solo las aplica. Lo que parece ocurrir es que el juez no quiere tomar la responsabilidad de resolver por el mismo, como que le da miedo. El hecho es que al interpretar, también le atribuye significado a los textos y signos, argumenta y crea las respuestas jurídicas.

El hecho es que el juez debe comenzar por reconocer que no se enfrenta solo a un lenguaje natural o a definiciones estipulativas, sino a elementos lexicales ambiguos que requieren de significación, que no siempre es posible bajo la lógica deductiva. Aunque se esconda bajo el mito de que es la ley la que resuelve, el hecho incontrovertible es que son los jueces los que dicen cuál es el contenido de proposiciones amorfas.

Nuestros jueces deben percatarse que el legislador, por lo general, ha establecido intencionalmente en el texto de las leyes, expresiones jurídicas vagas o ambiguas para que sea el juez quien resuelva el caso concreto, esto es, que al adoptar una decisión, le de contenido a la misma. El juez se encara a la posibilidad de tener diversas interpretaciones. Esto se advierte en las disposiciones del Derecho internacional privado, toda vez que con estas se pretende la armonización de sistemas al momento de resolver.

Debido a lo anterior, resulta importante, superlativamente importante para los juristas, conocer el aspecto funcional del derecho y no solo el aspecto estructural. Las explicaciones escolásticas no son las únicas.

Ojala que los jueces expresaran su experiencia sobre lo que hacen al interpretar, lo que enriquecería la doctrina y resolvería algunos problemas sobre racionalidad práctica, que es precisamente donde los teóricos carecen de experiencia. Con esto, ensancharían el desarrollo del DIPr. 